\title{
Crecimiento y Metabolismo: La Regulación y la vía de la InsULINA DESDE LA MosCA DE LA FrUtA, Drosophila melanogaster
}

\author{
Deyannira Otero-Moreno, María Teresa Peña-Rangel \\ y Juan Rafael Riesgo-Escovar* \\ Laboratorio de Genética de Transducción de Señales, Departamento de \\ Neurobiología del Desarrollo y Neurofisiología, Instituto de Neurobiología, \\ Universidad Nacional Autónoma de México. Boulevard Juriquilla, \#3001, \\ Campus UNAM-Juriquilla, Querétaro, Querétaro, C.P. 76230, México. \\ E-mail: *juanriesgo@prodigy.net.mx
}

\begin{abstract}
Resumen
Drosophila melanogaster, la mosca de la fruta, es un organismo genético modelo que en años recientes se ha usado exitosamente para estudiar el control del metabolismo y el crecimiento. A pesar de poseer algunas diferencias con las vías de señalización homólogas a las de los vertebrados, las semejanzas son profundas y claras. En D. melanogaster, la vía de la insulina, homóloga a la de los vertebrados, regula tanto el metabolismo como el crecimiento del organismo a través de un receptor membranal único. A su vez, esta vía-que conjunta lo que en vertebrados es la vía de la insulina y la de los péptidos parecidos a la insulina- está regulada por la ingesta de nutrientes (carbohidratos y proteínas) y por el control hormonal (hormona del crecimiento, ecdisona, upd2, hormona adipocinética, Ilp8). En consecuencia, normalmente se obtiene un crecimiento adaptable a las condiciones nutricionales que influye, como en los vertebrados, en el promedio de vida y en la capacidad reproductiva con un tamaño típico y una diferenciación armónica, a tono con el bauplan del organismo. Por el contrario las mutaciones y desviaciones dan por resultado partes desproporcionadas, menor capacidad reproductiva, y disminución tanto del tamaño como de la proliferación, y hasta la muerte. Palabras Clave: Carbohidratos, crecimiento, Drosophila melanogaster, lípidos, metabolismo, vía de la insulina.
\end{abstract}

\section{Growth and Metabolism: Regulation and the Insulin Pathway from a Fruit Fly's Viewpoint}

\begin{abstract}
The fruit fly Drosophila melanogaster is a model genetic organism that has recently been used with great success in the study of metabolism and growth controls. In spite of several differences with vertebrates, commonalities are many and extensive. In flies, the insulin pathway, homologous to the vertebrate pathway, regulates metabolism, growth, and proliferation through a single, common membrane receptor. This pathway, jointly taking over the functions exerted by vertebrate insulin and insulin-like peptides, is regulated by nutrient levels (dietary carbohydrates and proteins), and by hormonal control (juvenile hormone, ecdysone, upd2, adipokinetic hormone, Ilp8). This means that normally growth, size, and harmony of body parts are adapted to the nutritional status, influencing life expectancy and reproduction, and resulting in the wild type in reaching typical adult sizes and proportions, as expected from the bauplan. Mutations and deviations normally end up in disproportionate growth of body parts, overall reduced size and reproduction, and, ultimately, death. Key Words: Carbohydrates, growth, Drosophila melanogaster, lipids, metabolism, insulin pathway.
\end{abstract}

Nota: Artículo recibido el 24 de noviembre de 2015 y aceptado el $\mathbf{2 7}$ de abril de 2016. 


\section{INTRODUCCIÓN}

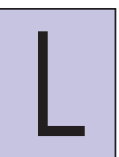

a mosca de la fruta, D. melanogaster, ha sido utilizada por más de cien años como un organismo genético modelo. Reconocida durante mucho tiempo por ser líder en el desarrollo y estudio de la genética y después como pionera y piedra "Rosetta" en los inicios de la biología del desarrollo moderno, D. melanogaster se ha revelado en los últimos años como un excelente modelo para estudiar el control del metabolismo, el crecimiento y la proliferación ${ }^{1-3}$. D. melanogaster posee una muy bien conservada vía de señalización de la insulina, que aglutina en una sola vía los efectos dispersos en vertebrados de la vía homónima, y de las vías de los factores de crecimiento parecidos a la insulina ${ }^{4}$. Además, por el rigor científico con el que se realizan los experimentos en D. melanogaster con: cepas genéticas homogéneas, gran número de individuos, mutantes a todos los niveles de señalización, tanto de falta de función como de función ectópica, experimentos bioquímicos, medición en diferentes estadíos del desarrollo, estudios horizontales, etc., el resultado son investigaciones más exactas y fiables. Finalmente, D. melanogaster también posee un control general del crecimiento y proliferación centrado en la comunicación entre órganos y tejidos operado por hormonas (hormona juvenil, ecdisona, upd2, hormona adipocinética, etc. $)^{5}$ y una relaxina parecida a la insulina (Ilp8 $)^{6-9}$, que regulan de manera parecida a las hormonas de los vertebrados, el metabolismo y el crecimiento armónico.

En principio, para poder regular de manera ajustable a las condiciones ambientales el crecimiento, la proliferación, la capacidad reproductiva y con ello, la sobrevida promedio, se requieren dos entradas principales al sistema: a) la disponibilidad de nutrientes (tanto aminoácidos derivado de la ingesta de proteínas, como de hidratos de carbono y lípidos) y b) el estado general de desarrollo y diferenciación del organismo. Esta información se procesa en varios órganos (tejido graso, cerebro, músculos e intestino), usando a la vía de la insulina como salida 'efectora', regulando el metabolismo y el crecimiento. La activación de la vía de la insulina, una vía anabólica, señala el crecimiento, aprovechamiento y almacenaje de nutrientes, primeramente de hidratos de carbono. La vía nominalmente contraria es catabólica, equivalente a la vía del glucagón en los vertebrados. Esta segunda vía se conoce aún poco en la mosca, fuera de que existe un ligando (hormona adipocinética) y un receptor de membrana conocido como el receptor de la hormona adipocinética ${ }^{10}$. El papel que juega en el metabolismo parece ser complejo ${ }^{11}$, y normalmente señala la falta de nutrientes, y el desdoblamiento de las reservas de glucógeno para proveer de glucosa al organismo, y la presencia de trehalosa en la hemolinfa (la hemolinfa es la 'sangre' de las moscas) ${ }^{11}$.

\section{Coordinación Hormonal en el Organismo del Crecimiento y Diferenciación Hormona Juvenil}

La hormona juvenil( $\mathrm{JH}$, por sus siglas en inglés) es una hormona lipídica (un sesquiterpeno) producida por la glándula endócrina llamada corpora allata. El corpora allata forma parte de la glándula en forma de anillo. La glándula en forma de anillo es una glándula endócrina vecina al cerebro de la mosca, que secreta varias hormonas. La secreción de la JH promueve, al igual que la insulina, el crecimiento larvario, función de la que proviene su nombre de 'hormona juvenil'. Durante las tres etapas larvarias de las moscas éstas crecen muchas veces su tamaño larvario inicial. Cada etapa larvaria termina con una muda del exoesqueleto y la síntesis de otro mucho más grande. Este crecimiento larvario ocurre junto con la activación de la vía de la insulina. Cuando las moscas son adultas ya no crecen en tamaño ni tienen mudas.

\section{Ecdisona}

Su contraparte, la hormona esteroide ecdisona, producida por el corpora cardiaca, otra porción de la glándula en forma de anillo, señala el inicio de la metamorfosis, y el fin de las etapas larvarias de crecimiento. En general se piensa que la JH promueve el crecimiento, pero no el cambio de estadío, mientras que la ecdisoma promueve cambios de estadío y frena el crecimiento ${ }^{12}$. Ambas hormonas forman asas de retroalimentación con la vía de la insulina, con lo que se puede regular de manera precisa el crecimiento y la diferenciación, y en algunos casos, el crecimiento diferencial de órganos y sistemas, y aún de castas, como sucede con las abejas que se diferencian entre reinas y obreras por un componente de la jalea real, la royalactin (su nombre en inglés), que entra en función por la activación de la vía de las MAPcinasas (o cinasas activadas por mitógenos, por sus siglas en inglés $)^{13}$.

\section{IIp8}

El crecimiento se debe de balancear. Por ello se necesita un sistema que opere para asegurar que las diferentes partes del cuerpo crezcan de manera armónica y simétrica. Ilp8, un péptido parecido a la insulina semejante a la relaxina se requiere para esto. Las mutantes de Ilp 8 crecen, pero tienen frecuentes desproporciones ${ }^{8,9,14}$. Este péptido opera a través de un receptor distinto al de los otros péptidos que son parecidos a los factores de crecimiento semejantes a la insulina de los vertebrados (Ilp, por sus siglas en inglés). Ilp 8 se une a un receptor de membrana de siete pases transmembranales, $\lg r 3$, que actúa a través de la elevación del segundo mensajero AMPc intracelularmente, en dos pares de neuronas del cerebro medio que contactan a las neuronas neurosecretoras de los Ilp que son el grupo de neuronas productoras de insulina (o las IPC, por sus siglas en inglés) y a las neuronas PTTH (por sus siglas en inglés, 
prothoracicotropic hormone). Las neuronas PTTH secretan la hormona protoracicotrófica, que regula la secreción de la hormona ecdisona en la glándula protorácica ${ }^{6}$. Dado que el Ilp 8 se secreta de los discos imagales (los tejidos imagales son tejidos de origen larvario ectodérmicos que dan lugar durante la metamorfosis a la mayoría de las estructuras adultas, como las patas, alas, etc.), señalando el estado de los mismos, sirve para balancear y regular el crecimiento de éstos, y evitar los defectos (Figura 1).

\section{Ingesta y Metabolismo}

Después de la ingesta y digestión de alimentos, éstos pasan a la hemolinfa. Las células productoras de los Ilp (ver más abajo), que son siete péptidos en la mosca (exceptuando el Ilp8, que es más bien un homólogo de la relaxina de los vertebrados ${ }^{8,9}$ ) se sintetizan y secretan en varios tejidos (ver mas abajo), pero principalmente a partir de un grupo de neuronas en el cerebro medio, las IPC.

Las IPC se localizan dentro de la barrera hematoencefálica, por lo que no están en contacto directo con la hemolinfa

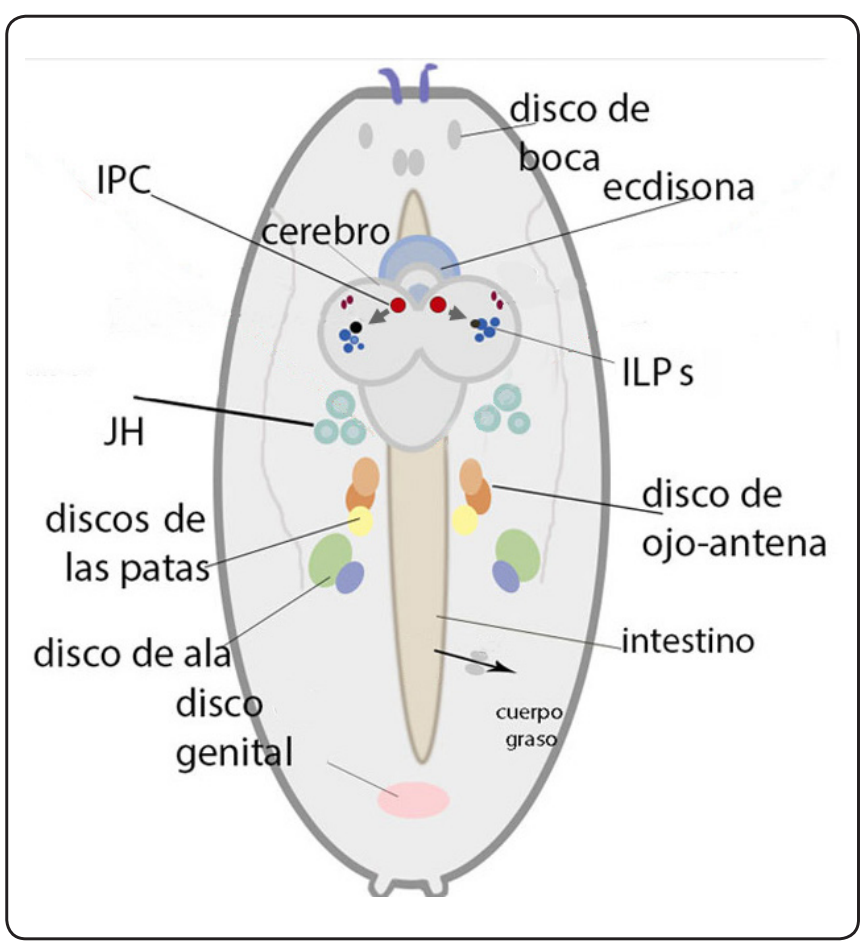

Figura 1A. Esquema de un embrión de D. melanogaster mostrando la localización del cerebro, el intestino y los discos imagales. Se muestra la localización de las células secretoras de péptidos parecidos a la insulina (IPC), que secretan los IIp, así como algunas de las influencias hormonales que tendrán las IPC en su vida larvaria (la ecdisona y la hormona juvenil, JH). Un flecha negra muestra la salida del intestino y la incorporación de nutrientes hacia la hemolinfa. Es una vista dorsal con la parte posterior hacia abajo.
(Figura 2). Sin embargo, son capaces, como las células beta de los islotes de Langerhans del páncreas de mamíferos, de percibir glucosa en el medio. Estas neuronas se depolarizan si hay glucosa extracelular, mediado por el cierre de un canal de potasio sensible a ATP (ocurre, en principio, una elevación de ATP como consecuencia del aprovechamiento de la glucosa en la fosforilación oxidativa en sus mitocondrias para generar ATP en las IPC, y alterar la relación de ATP/ADP). Este cierre del canal de potasio sensible a ATP provoca una despolarización de las IPC. Además de este canal, el canal de potasio activado por calcio (y voltaje), slowpoke, y la proteína que une a slowpoke que modifica su comportamiento, slob, se requieren para la excitabilidad de las IPC. Las mutaciones en estas dos proteínas dan por resultado fenotipos de falta de función en la vía de la insulina, porque las IPC secretan menos $I l p^{15}$.

La despolarización, a su vez, provoca la apertura de canales de calcio sensibles al voltaje, la entrada de calcio extracelular, y la generación de potenciales de acción que permiten la secreción de los Ilp de las IPC ${ }^{16,17}$. Existen también tres proteínas desacoplantes en el genoma de la mosca, pero no se sabe mucho

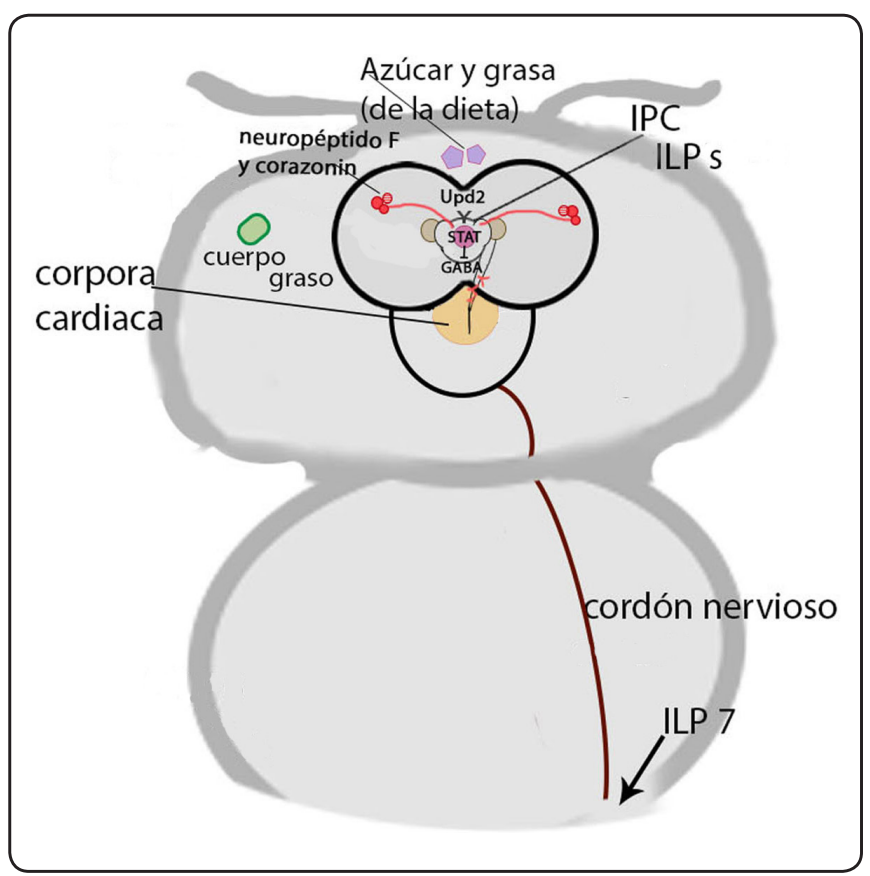

Figura 1B. Esquema de la cabeza de un adulto de $D$. melanogaster mostrando el cerebro, con algunas de las influencias que tienen las IPC. Se ven a las neuronas que secretan GABA, y que responden a Upd2 secretado por el cuerpo graso. La recepción de Upd2 inhibe a estas neuronas, que normalmente inhiben a las IPC. También se muestran las terminaciones que secretan el neuropéptido $F$ y la corazonin de neuronas que están en el ganglio subesofágico, y que regulan a las IPC. Se muestra como un hilo café el cordón ganglionar ventral, algunas de cuyas neuronas secretan Ilp. Vista dorsal con anterior hacia arriba. 


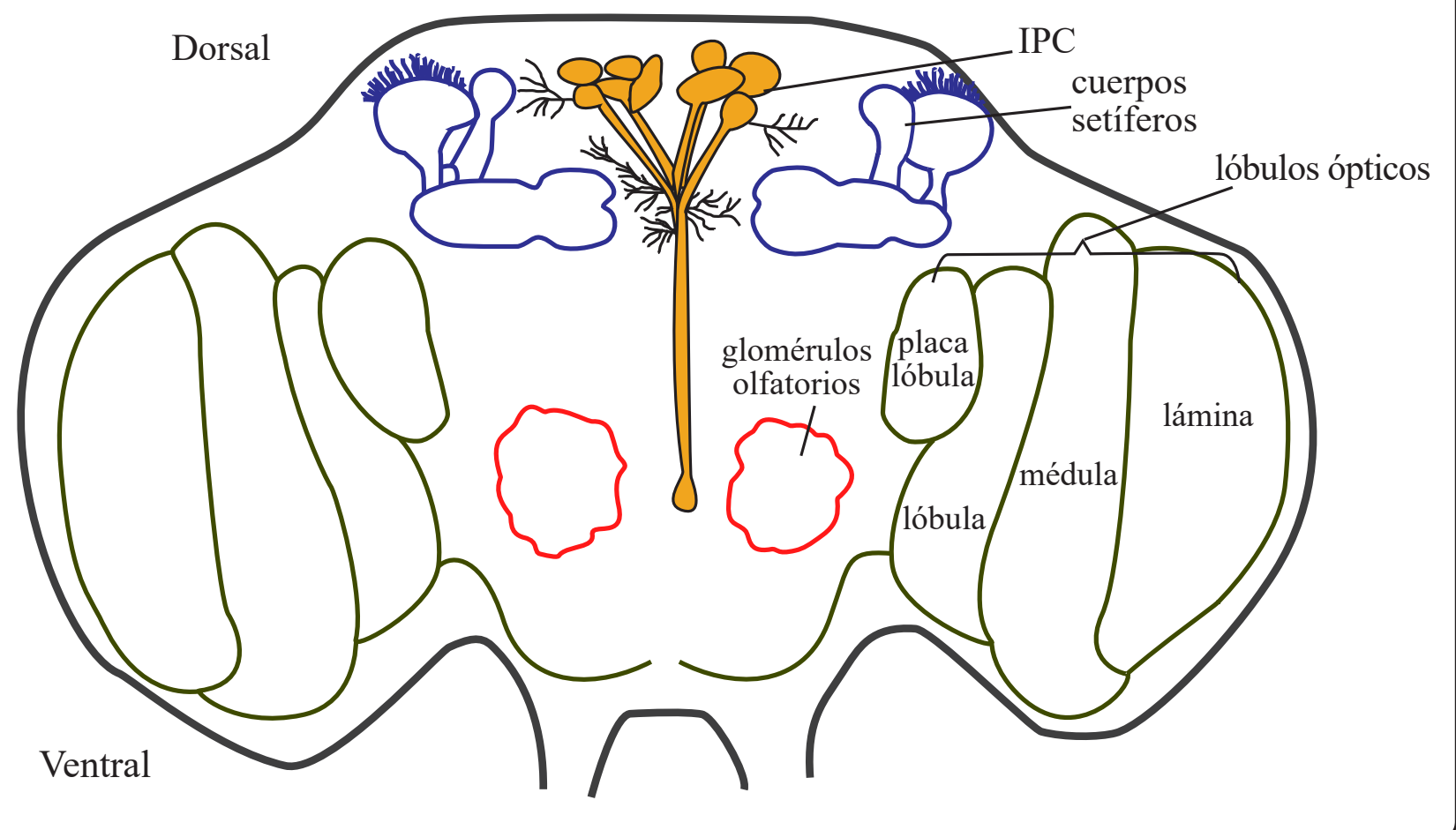

Figura 2. Localización de las células secretoras de los Ilp en el cerebro adulto de la mosca de la fruta. El esquema muestra la localización aproximada de estos dos grupos de células (un grupo consiste de aproximadamente quince células en la parte medio-dorsal de cada hemisferio cerebral) en relación con los cuerpos setíferos, los lóbulos ópticos y los glomérulos olfatorios. El esquema no está a escala. Modificado de Nassel, D.R. et al. ${ }^{18}$

de ellas ${ }^{19}$; sin embargo, en estudios con expresión ectópica en las IPC, con homólogas de los vertebrados, se observó que su actividad desacoplante regula la secreción de las Ilp de las IPC, sugiriendo que el nivel de actividad de la fosforilación oxidativa regula la secreción. Además de lo anterior, las IPC requieren al menos otra entrada para regular la secreción de los Ilp: si es cierto que es fisiológico que la glucosa existente en el ambiente extracelular vecino a las IPC se usa para determinar la cantidad de hidratos de carbono ingeridos, debe entonces de existir un sistema de transporte de la glucosa a este espacio desde la hemolinfa, que refleje qué cantidad de ésta hay en ella. Por otra parte, también se tienen que sensar los niveles de aminoácidos (y de lípidos) para, ciñéndose también a ellos, se regule la proliferación y el crecimiento.

La elevación de los niveles de aminoácidos, y posiblemente también de los carbohidratos y lípidos en la hemolinfa es sensado por células del cuerpo graso, lo que, al menos en el caso de los aminoácidos, ocurre a través de un mecanismo que se desconoce, pero que requiere del transportador de aminoácidos slimfast. Mutaciones en slimfast dan como consecuencia animales de menor talla, con desarrollo retardado y desarreglos metabólicos, lo que implica que el paso por este transportador es crítico para el senso nutricional que se lleva a cabo en el cuerpo graso $^{20}$. En casos extremos, las mutantes de slimfast, como mutaciones en genes que codifican para componentes de la vía de la insulina, son letales ${ }^{19}$.

El cuerpo graso es un órgano equivalente al hígado y tejido adiposo de mamíferos. Hasta donde se conoce, actúa como integrador de la información nutricional, puesto que la falta de al menos uno de los nutrientes básicos (aminoácidos, y de entre ellos, se cree también que la ausencia de metionina es muy importante), es suficiente para evitar la señal de 'saciedad'y con ello, la activación del anabolismo y el crecimiento. Este efecto normalmente se ejerce después de varios pasos de transducción, a través de la activación de la vía de la insulina en varios tejidos ${ }^{5}$. El cuerpo graso se comunica con células secretoras en el cerebro a través de mensajeros hormonales cuando hay nutrientes en la hemolinfa, para promover el anabolismo y el crecimiento.

unpaired2 (upd2) es uno de estos mensajeros. upd2 es una citosina de tipo I de función homóloga a la leptina de los mamíferos, la hormona que en estos últimos señala saciedad. Aunque la secuencia primaria de la leptina y upd 2 son distintas, la leptina humana puede sustituir funcionalmente a upd 2 en la $\operatorname{mosca}^{5}$, por lo que la estructura tridimensional debe de ser muy parecida. 
No se ha descrito todavía a un homólogo de la adiponectina en la mosca, una hormona que potencia el efecto de la insulina, pero existe un receptor de adiponectina (adipoR) en $D$. melanogaster con efectos, como en los mamíferos, de potenciación de la insulina. Se piensa que del mismo modo que upd 2 y la leptina no se parecen pero son funcionalmente equivalentes, asimismo debe de existir un gen que codifique para una proteína equivalente funcional a la adiponectina en la mosca y que éste debe ser un factor secretado también por el cuerpo graso para señalar saciedad. El AdipoR se expresa en las células secretoras de los Ilp del cerebro, las IPC ${ }^{21}$.

De esta manera el cuerpo graso comunica al cerebro el estado nutricional del organismo sensando aminoácidos, y posiblemente también grasas y carbohidratos. Se sabe que un grupo de neuronas gabaérgicas, que normalmente inhiben la secreción de insulina en las IPC, expresan el receptor de upd2, domeless (dome), y la vía de señalización $\mathrm{JAK} / \mathrm{STAT}^{22}$. Esto hace posible que se active en estas neuronas la vía de JAK/STAT. Esto último resulta en la inhibición de la secreción de Gaba. Normalmente estas neuronas gabaérgicas inhiben a las IPC, por lo que su inhibición ahora resulta en una desinhibición de las IPC, que entonces secretan insulina. Además, las IPC expresan el receptor AdipoR, que recibe la señal de una molécula no identificada equivalente a la adiponectina, potenciando la secreción a la hemolinfa de varios péptidos parecidos a la insulina.

Además del cuerpo graso, las células gliales de superficie también integran información nutricional a partir de la hemolinfa: expresan slimfast, el receptor de insulina, integran la información y secretan Ilp6. Neuronas colinérgicas que sirven de enlace con las IPC, responden a la señal secretando otro mensajero que activa la vía de la insulina en las IPC (ver más abajo) para que estas secreten Ilp5 ${ }^{23}$. Es posible que existan otros tipos de células o tejidos que localmente integren información nutricional $\mathrm{y}$ sinteticen un mensajero para las IPC.

De esta forma, las IPC reciben información del entorno extracelular vecino, del cuerpo graso, de las células gliales de superficie, y de otras neuronas, para regular la secreción de los Ilp.

\section{PÉPtidos Parecidos a la insulina en la mosca (ILP) Y SU REGULACIÓN}

En general, varios de los Ilp actúan conjuntamente en dos aspectos: a) como la insulina de los vertebrados, una hormona anabólica que estimula la absorción de la glucosa y su almacenamiento en forma de glucógeno y b) como los factores de crecimiento parecidos a la insulina de los vertebrados, que como su nombre lo indica, promueven el crecimiento y la proliferación.

Los péptidos parecidos a la insulina en la mosca son ocho. Ilp1, 2,3 y 5 se secretan de las IPC y median los efectos en muchos tejidos, ya que las IPC tienen terminaciones en el corazón tubular de la mosca, de donde se cree que se secretan a la hemolinfa ${ }^{24}$. No todos los Ilp se secretan por los mismos estímulos y aunque los Ilp1-7 se unen al mismo receptor, tienen efectos que no son completamente redundantes y, por lo tanto, presentan fenotipos distintos. Los más parecidos en secuencia a la insulina de los vertebrados son los Ilp1-5 ${ }^{24}$.

También, diferentes Ilp se producen (además de en las IPC) en diferentes etapas del desarrollo y en diferentes tejidos. Ilp 1, 2, 3 y 5 se sintetizan en las fases larvarias y en el adulto por las IPC. Ilp6 se sintetiza en la larva y en el adulto en el cuerpo graso, y Ilp8 en los discos imagales ${ }^{25}$. Varios Ilp se expresan (Ilp2-5 y $I l p 7$ ) en el mesodermo y en el intestino, en donde se piensa que también señalizan saciedad, e Ilp6-7 en el sistema nervioso.

Ilpl tiene efectos muy moderados sobre el crecimiento. La sobreexpresión generalizada de Ilp4, que normalmente se expresa en el intestino, tiene efectos moderados en el crecimiento, por lo que se piensa que contribuye a la señalización global de la saciedad, e Ilp7 regula la decisión de ovipositar en las hembras ${ }^{1}$. Ilp2, 3 y 5 son los Ilp con mayores efectos sobre el crecimiento y el metabolismo.

\section{IIp2 y 3}

En las larvas, Ilp2 se secreta en respuesta a los aminoácidos, mientras Ilp3 en respuesta a la trehalosa en la hemolinfa. La trehalosa es detectada en la hemolinfa por las células del corpora cardiaca, parte de la glándula en forma de anillo, que secretan la hormona adipocinética. En la mosca, se ha descrito este sistema para señalar la presencia de trehalosa, ya que la hormona adipocinética activa el receptor de la hormona adipocinética en las IPC, y éstas secretan entonces Ilp3 a la hemolinfa, activando la vía de la insulina en tejidos periféricos ${ }^{11}$. El locus de la hormona adipocinética regula los niveles de trehalosa, y es otra entrada de regulación sobre las IPC ${ }^{1}$.

\section{IIp5 y 6}

Las células gliales de superficie perciben el estado nutricional del organismo a través de la hemolinfa, y en respuesta a los aminoácidos y los Ilp, secretan Ilp6 hacia el interior del cerebro. Neuronas colinérgicas vecinas a estas células gliales y a las IPC reciben la señal de Ilp6, activan la vía de la insulina, y en respuesta secretan el péptido jellybelly (jeb) que se une a un receptor de membrana parecido al receptor de insulina llamado anaplastic lymphoma kinase o Alk, por sus siglas en inglés en las IPC, y esto activa por debajo del receptor de insulina a la vía de la insulina en las IPC, que en consecuencia, secretan Ilp5 $5^{23,26}$. Esto representa otra entrada más a las IPC ${ }^{11,26-27}$.

Cuando experimentalmente faltan las IPC en el cerebro de las moscas, se genera una situación parecida a la Diabetes mellitus tipo I, en donde no se producen suficientes Ilp, como en los pacientes en donde no se produce insulina por daño a 
las células beta de los islotes de Langerhans del páncreas. Sin embargo, estas moscas son viables, aunque hay un aumento de carbohidratos en la hemolinfa en condiciones de ayuno, a semejanza de los diabéticos. También presentan aumento de los carbohidratos y lípidos de reserva, una menor capacidad reproductiva, una mayor sensibilidad al calor y al frío, retardos en el crecimiento, en el desarrollo, y una talla reducida. En contraparte, exhiben resistencia a la falta de comida, y tienen una mayor longevidad ${ }^{24,28}$. La razón por la que son viables es que secretan Ilp otros tejidos, y esas secreciones son suficientes para la viabilidad, pero no para las muchas otras funciones que desempeñan los Ilp, poniendo de relieve el papel central que juegan las IPC en la vía de la insulina.

\section{Factores Regulatorios eXtracelulares de los ILP}

Existe una proteína secretada regulatoria de los Ilp llamada Imaginal Morphogenesis Protein-Late 2 (IMP-L2), por sus siglas en inglés ${ }^{29}$, homólogo de los insulin-like growth factors binding proteins, o proteínas que unen a los péptidos que son factores de crecimiento parecidos a la insulina. La IMP-L2 captura en un complejo con otra proteína secretada, Als (Acid labelled subunit, por sus siglas en inglés $)^{30}$, al menos a Ilp2 y 5 en el espacio extracelular. Esto evita que Ilp 2 y 5 se unan al receptor de insulina, regula negativamente la señal de estos Ilp. Finalmente existe otra proteína secretada que es semejante a la porción extracelular del receptor de insulina llamado Secreted Decoy of insulin Receptor (SDR, por sus siglas en inglés) ${ }^{31}$, que secretan las células gliales a la hemolinfa de manera constitutiva, y que captura a los Ilp evitando que interactúen con el receptor de insulina en el espacio extracelular.

\section{Sistema Nervioso en el Control de las IPC}

Además de las IPC, otras neuronas expresan los Ilp. Hay alrededor de veinte neuronas en el ganglio subesofágico que expresan $I l p 7$, algunas de las cuales expresan también el neuropéptido $F$ corto y posiblemente acetilcolina, y algunos de sus axones terminan cerca de las IPC, sugiriendo una regulación de éstas por el neuropéptido F corto, acetilcolina e $\operatorname{Ilp} 7^{1,18}$. Esto implica que tanto jellybelly como Ilp 7 activan la vía de la insulina en las IPC para activar la secreción de los Ilp. Por otro lado, Ilp6 secretado del cuerpo graso actúa en las IPC para inhibir la secreción de los Ilp. El neuropéptido F (tanto el corto como el largo) influye en la conducta de alimentación y sus niveles circulantes están, a su vez, regulados por la vía de la insulina. El receptor para el neuropéptido F se expresa en las IPC, y activa a la vía de las MAPcinasas (como la royalactin), y a través de la activación de las MAPcinasas se activa la secreción de los $I l p^{32}$, lo que hace comprensible el por qué la royalactin también tiene efectos en $D$. melanogaster ${ }^{13}$. Las neuronas que secretan el neuropéptido $F$ también co-secretan el neuromodulador corazonin, y el receptor de corazonin se expresa en las IPC. La reducción de la expresión de corazonin o de su receptor reduce la función de las IPC, alterando el metabolismo ${ }^{33}$.
Existen neuronas serotoninérgicas, que expresan la GTPasa NS3, que regulan el crecimiento y el metabolismo a través de la vía de la insulina ${ }^{34}$. Las IPC expresan el receptor de histamina 5-HT ${ }_{\text {IA }}$, que en condiciones mutantes de falta de función, desregula la vía de la insulina ${ }^{35}$. Los productos del locus de la taquicinina, un neuromodulador, se expresan en el cerebro, y uno de sus receptores se expresa en las IPC. Mutantes de falta de función de este receptor en las IPC tienen fenotipos que sugieren que la taquicinina regula los transcritos de los Ilp en las IPC ${ }^{36}$.

Las IPC tienen receptores a la octopamina, y esta amina biogénica regula patrones de vigilia/sueño a través de la activación de las IPC aumentando el AMPc intracelular, pero no se sabe si esta regulación afecta la secreción de los $I l p^{18}$. Además de la taquicinina, octopamina y la serotonina, otros neuromoduladores regulan/modifican la actividad de las IPC. Entre ellos se ha sugerido a la alostatina A, y las hormonas diuréticas 31 y 44 . Las dos primeras se secretan en el intestino medio, y podrían servir de señalizadores de la ingesta y digestión de comida, ya que las IPC tienen receptores a estos neuromoduladores ${ }^{18}$. También se ha sugerido que el receptor Gr43A, sensible a la fructosa, este último un disacárido presente en la dieta de la mosca, puede ser percibido por neuronas en el cerebro que se conectan con las IPC, e influir en la actividad de éstas ${ }^{37,38}$. Algunas IPC secretan Drososulfacininas, que señalan saciedad ${ }^{18,39}$. Los olores pueden modificar la secreción de insulina: olores a comida por periodos de tiempo breves aumentan la secreción de los Ilp, y el comportamiento de alimentación, mientras que exposiciones prolongadas derivan en saciedad ${ }^{40}$.

Finalmente, algunos de los Ilp pueden ser partes de asas de retroalimentación y regular la secreción de los mismos ${ }^{18}$.

En resumen, la capacidad de las IPC de percibir carbohidratos directamente y de responder a los mismos, la diversidad de péptidos parecidos a la insulina (Ilp), con funciones sólo parcialmente redundantes, secretados en distintos tejidos y a distintos tiempos, y los reguladores extracelulares (IMP-L2, ALS, SDR), además de la regulación hormonal por otros tejidos y neural, muestran un nivel de regulación complejo al inicio de la señalización de la vía de la insulina.

\section{VíA DE LA INSULINA EN LA MOSCA}

Una vez que se secretan los Ilp 1-7 al espacio extracelular, éstos, si no son capturados por proteínas que unen a los $I l p$ (ver arriba), interactúan con el receptor de insulina en la mosca ${ }^{4,41}$ (Figura 3). Este receptor de membrana, que posee dos isoformas, se activa por fosforilación cruzada en residuos de tirosina, y fosforila a proteínas adaptadoras (conocidas como IRS, por sus siglas en inglés, insulin receptor substrates) en la mosca: chico $^{42}$ y $\ln k^{43-45}$. Ésto genera sitios de unión para otras proteínas en la membrana plasmática, como la subunidad reguladora de la fosfatidilinositol 3 cinasa (o PI3K, por sus siglas en inglés, 


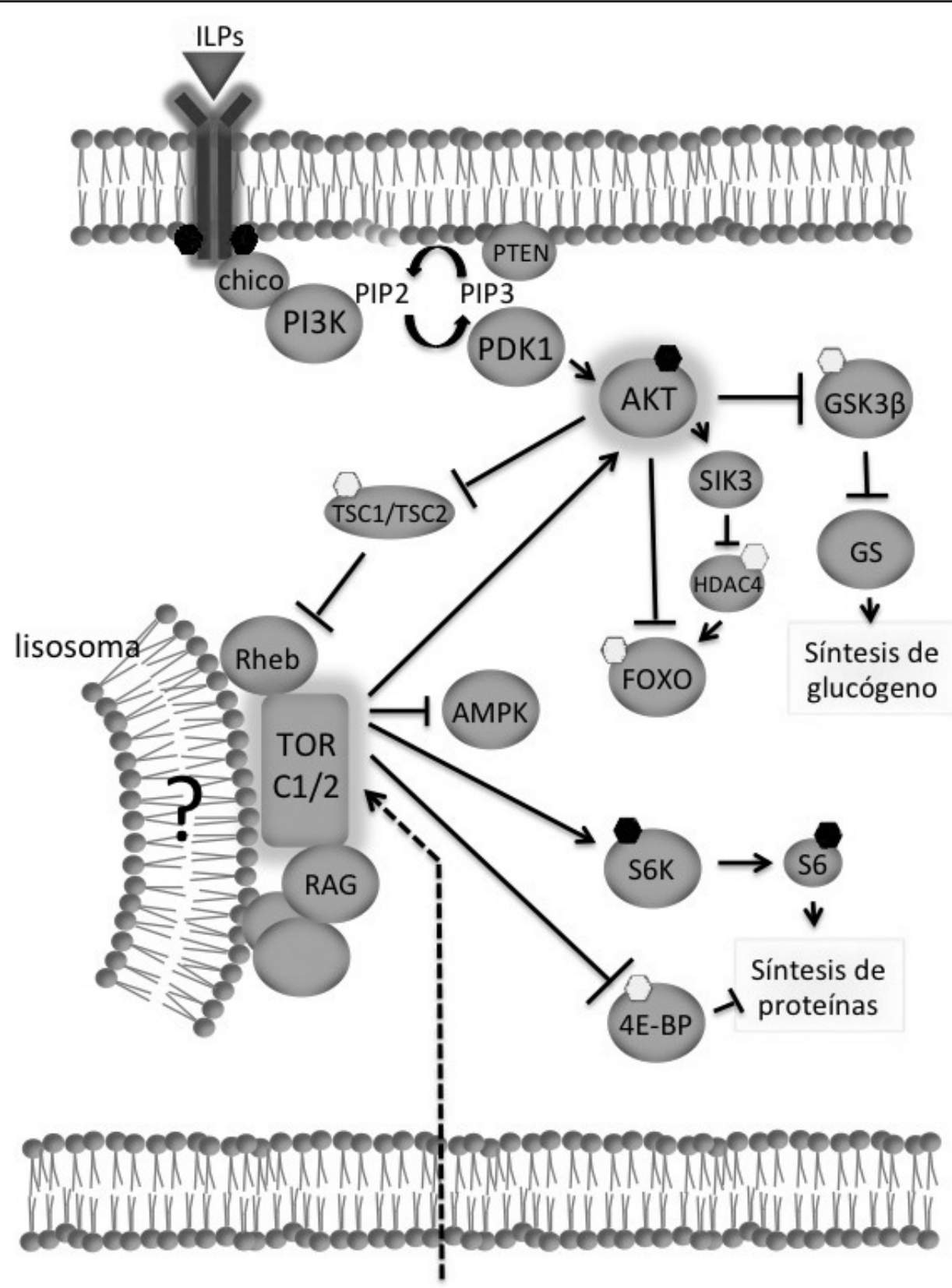

nutrientes

Figura 3. La vía de la insulina en la mosca de la fruta. Los péptidos parecidos a la insulina/factores de crecimiento semejantes a la insulina (Ilp, en forma de triángulo) se unen al receptor de insulina (receptor) y éste se autofosforila (en forma de hexágonos). Ésto crea sitios de unión para proteínas de anclaje como Chico. La fosfatidilinositol 3 cinasa (PI3K) se une a Chico y al receptor activado, y genera fosfatidilinositoltrisfosfato (PIP3) de fosfatidilinositol bisfosfato (PIP2), y genera sitios de unión para PDK1 (proteína cinasa 1), que fosforila y activa a AKT (proteincinasa B). La fosfatasa PTEN cataliza la reacción contraria, de PIP3 a PIP2 y forma un asa de retroalimentación negativa. AKT fosforila e inhibe (hexágonos) a GSK3 $\beta$ (la glucógeno sintasa cinasa $\beta$ ), que activa a la glucógeno sintasa (GS), a Foxo, y al complejo TSC1/TSC2 (complejo de esclerosis tuberosa, con actividad de GAP), que normalmente inhibe a la proteína G monomérica Rheb. AKT también activa a la cinasa inducida por sal (Sik3), que inhibe a una deacetilasa (HDAC4), que normalmente activa a Foxo. El complejo de RAG (con actividad de proteína G parecido a Ras) y Rheb activan al complejo TOR (TORC1/2) y esta cinasa, TOR, fosforila y activa a la cinasa S6K, que fosforila y activa a la proteína del ribosoma S6 para activar la síntesis de proteínas. El complejo TOR inhibe a la proteína que une al factor de elongación 4E (4E-BP), ya que éste último normalmente inhibe la síntesis de proteínas. TOR también inhibe a la cinasa de AMP (AMPK). Se ha sugerido que la activación del complejo TOR se lleva a cabo en los lisosomas. Fosforilaciones con efecto activador están marcados con hexágonos oscuros y fosforilaciones con efecto inhibidor con hexágonos claros. 
phosphatidylinositol 3 kinase), que fosforila a un lípido de membrana, el fosfatidilinositol bisfosfato (o PIP2, por sus siglas en inglés, phosphatidylinositol biphosphate), para convertirlo en fosfatidilinositoltrisfosfato (o PIP3, por sus siglás en inglés) ${ }^{46}$. Este fosfolípido une a la PDK1 (proteína cinasa 1, por sus siglas en inglés) ${ }^{47}$, que fosforila y activa a la proteincinasa B (PKB o AKT; oficialmente se le designa AKT en la mosca, aunque ambos nombres se refieren a la misma molécula, y vienen de sus siglas en inglés). AKT es una cinasa central en la vía, pues tiene varios blancos críticos para la señalización ${ }^{48}$. Una fosfatasa que actúa para desactivar a la vía es PTEN, que es la fosfatasa del PIP3, convirtiéndolo en PIP2 ${ }^{49}$.

AKT fosforila a varias proteínas: a) un blanco es la glucógeno sintasa cinasa $3 \beta$ (GSK3 $\beta$ ), conocida como shaggy en $D$. melanogaster, que al ser fosforilada por AKT se inhibe su acción sobre la glucógeno sintasa, y así libera a esta enzima anabólica para sintetizar glucógeno ${ }^{50}$. b) Otro blanco es el homólogo en la mosca de los factores de transcripción con dominio forkhead tipo $\mathrm{O}$, foxo, factor de transcripción que al ser fosforilado se exporta del núcleo y se degrada. Normalmente foxo activa el catabolismo y ayuda a la supervivencia en condiciones de poca comida, de modo que su activación puede ocurrir como consecuencia de la activación del anabolismo ${ }^{51-53}$. c) Otro blanco es una de las proteínas del complejo tsc $1 / 2$ (cuyas siglas vienen del inglés de tuberous sclerosis complex), la tsc2, , llamado gigas en $D$. melanogaster. tsc $1 / 2$ es un complejo descubierto inicialmente en el síndrome humano de esclerosis tuberosa. Los pacientes con este síndrome desarrollan tumores benignos en varios tejidos. En la mosca este complejo también es catabólico, de manera que su inactivación es por fosforilación de gigas ${ }^{54-56}$. El complejo tsc1/2 inhibe, actuando como una GAP (GTPase activating protein, por sus siglas en inglés; las Gap actúan acelerando la hidrólisis en proteínas G monoméricas de GTP a GDP más fosfato inorgánico) a Rheb, una proteína $\mathrm{G}^{57,58}$ que activa a la cinasa TOR (ver más abajo), y la fosforilación de gigas evita la formación del complejo ${ }^{59}$. d) AKT también fosforila a las salt-inducible-kinase3, o sik3, por sus siglas en inglés, y ésta a su vez regula a una deacetilasa, HDAC4, que normalmente deacetila a Foxo y lo activa, de manera que cuando Sik3 fosforila a HDAC4, la inactiva, y Foxo permanece acetilado e inactivo ${ }^{60}$.

Al igual que en los vertebrados, la cinasa de serina-treonina TOR (target of rapamycin, por sus siglas en inglés), es un integrador de la información crítica para el control del crecimiento, pues recibe información tanto de la parte de la vía de la insulina que viene del receptor de insulina, como de slimfast, el transportador de aminoácidos ${ }^{61}$. Forma dos complejos, TORC1 y TORC2. TOR en el complejo TORC1 es la proteína afectada por la droga rapamicina. La rapamicina es un compuesto que se aisló primeramente de bacterias colectadas en la isla de Rapa Nui, o la isla de Pascua, en Chile ${ }^{62}$.
La actividad de TOR se regula por $R$ heb directamente y por otra parte por las proteínas G monoméricas $\operatorname{Rag} A-B$ y $\operatorname{RagC} C-D$. Estas últimas proteínas $\mathrm{G}$ forman un heterodímero y regulan la actividad de TORC1 positivamente; transducen el mensaje de la presencia de aminoácidos en la célula ${ }^{63}$. En mamíferos se piensa que lo hacen -estando unidos a GTP- traslocando el complejo mTORC1 a la membrana del lisosoma, donde se encuentra $R h e b$. Rheb-GTP se une y activa a mTORC ${ }^{64}$. En D. melanogaster, las proteínas $\mathrm{G}$ de las familias Rab y Arf se requieren para la activación de TORC1 ${ }^{65}$. Dado que las Rab y Arf median el transporte intracelular, esto sugiere que al igual que en los mamíferos, TORC1 se trasloca intracelularmente, probablemente hacia la membrana del lisosoma para que sea activado por Rheb.

TORC1 fosforila y activa a varias proteínas ${ }^{66}$, entre ellas a la cinasa S6, que fosforila a la proteína ribosomal $\mathrm{S} 6 \mathrm{y}$ activa a los ribosomas $^{67,68}$. También fosforila a Elf4-BP ${ }^{69}$, el factor que une al factor de iniciación $4 \mathrm{E}$ de eucariotes, y al quitar la inhibición que tiene este factor sobre el factor de elongación $4 \mathrm{E}$ se inicia la traducción. TOR también fosforila a varios componentes de la vía de la insulina, regulándolos a la baja, como Tsc1, Gigas, PTEN y Rheb ${ }^{19}$. De este modo, TOR activa el anabolismo e inhibe el catabolismo.

Finalmente TORC1 también fosforila a la cinasa de AMP, o AMPK y la inhibe. Esta cinasa forma parte de un sistema evolutivamente muy antiguo de regulación de la nutrición, porque percibe la proporción que guarda en la célula el AMP, ADP y el ATP. Está constituida por tres subunidades (alfa, beta y gama) y estimula la síntesis de ATP cuando éste está bajo (catabolismo). Interacciona con otros elementos de la vía de la insulina, como Rheb y TSC2, pasando a imbricarse con la vía de la insulina ${ }^{70,71}$.

\section{Comentarios Finales}

La vía de la insulina coordina el estado nutricional y de desarrollo del organismo con el crecimiento. En ella convergen distintos estímulos (nutrición y estado del desarrollo), y a través de ella se integra la información para dar una respuesta coordinada en todo el organismo y regular el crecimiento.

El estudio de la vía de la insulina en D. melanogaster se ha convertido en un sofisticado modelo para el estudio del control del metabolismo, y para estudiar sus desviaciones, como la Diabetes mellitus $^{72}$. Existen muchos ejemplos en la literatura sobre el uso de la mosca, ya sea utilizando dietas especiales ${ }^{2,73}$, uso de mutantes hipomorfas de la vía ${ }^{74-75}$, o ablación de las células productoras de insulina ${ }^{76}$, que recapitulan los efectos de la Diabetes mellitus en la mosca. Esto es muy importante hoy en día, por la cercanía y conservación evolutiva de la vía, y el incremento de la enfermedad en la población mundial, particularmente, en México ${ }^{77}$. 


\section{Agradecimientos}

PAPIIT, proyecto \# 200313-25 a Juan Rafael Riesgo Escovar.

\section{Referencias}

1. Owusu-Ansah, E. \& Perrimon, N. Modeling metabolic homeostasis and nutrient sensing in Drosophila: implications for aging and metabolic diseases. Dis. Model Mech. 7,343-350, doi:10.1242/ dmm.012989 (2014).

2. Smith, W. W., Thomas, J., Liu, J., Li, T. \& Moran, T. H. From fat fruit fly to human obesity. Physiol. Behav. 136, 15-21, doi:10.1016/j.physbeh.2014.01.017 (2014).

3. Rubin, G. M. Drosophila melanogaster as an experimental organism. Science 240, 1453-1459 (1988).

4. Teleman, A. A. Molecular mechanisms of metabolic regulation by insulin in Drosophila. Biochem. J. 425, 13-26, doi:10.1042/ BJ20091181 (2010).

5. Rajan,A.\&Perrimon, N. Drosophila cytokine unpaired 2 regulates physiological homeostasis by remotely controlling insulin secretion. Cell 151, 123-137, doi:10.1016/j.cell.2012.08.019 (2012).

6. Vallejo, C. G., Juárez-Carreño, S., Bolívar, J., Morante, J. \& Domínguez, M. A brain circuit that synchronizes growth and maduration revealed through Dilp8 binding to Lgr3. Science 350, doi:10.1126/science.aac676 (2015).

7. Colombani, J. et al. Drosophila Lgr3 Couples Organ Growth with Maturation and Ensures Developmental Stability. Curr. Biol. 25, 2723-2729, doi:10.1016/j.cub.2015.09.020 (2015).

8. Colombani, J.,Andersen, D. S. \& Leopold, P. Secreted peptide Dilp8 coordinates Drosophila tissue growth with developmental timing. Science 336, 582-585, doi:10.1126/science.1216689 (2012).

9. Garelli,A., Gontijo,A.M., Miguela, V., Caparros, E. \& Domínguez, M. Imaginal discs secrete insulin-like peptide 8 to mediate plasticity of growth and maturation. Science 336, 579-582, doi:10.1126/science.1216735 (2012).

10. Pool, A. H. \& Scott, K. Feeding regulation in Drosophila. Curr. Opin. Neurobiol. 29, 57-63, doi:10.1016/j.conb.2014.05.008 (2014).

11. Kim, J. \& Neufeld, T. P. Dietary sugar promotes systemic TOR activation in Drosophila through AKH-dependent selective secretion of Dilp3. Nat. Commun. 6, 6846, doi:10.1038/ ncomms 7846 (2015).

12. Koyama, T., Mendes, C. C. \& Mirth, C. K. Mechanisms regulating nutrition-dependent developmental plasticity through organspecific effects in insects. Front Physiol. 4, 263, doi:10.3389/ fphys.2013.00263 (2013)

13. Kamakura, M. Royalactin induces queen differentiation in honeybees. Nature 473, 478-483, doi:10.1038/nature10093 (2011).

14. Andersen, D. S., Colombani, J. \& Leopold, P. Drosophila growth and development: keeping things in proportion. Cell Cycle 11, 2971-2972, doi:10.4161/cc.21466 (2012).

15. Sheldon, A. L., Zhang, J., Fei, H. \& Levitan, I. B. SLOB, a SLOWPOKE channel binding protein, regulates insulin pathway signaling and metabolism in Drosophila. PLoS One 6, e23343, doi:10.1371/journal.pone.0023343 (2011).

16. Fridell, Y. W. et al. Increased uncoupling protein (UCP) activity in Drosophila insulin-producing neurons attenuates insulin signaling and extends lifespan. Aging (Albany NY)
1, 699-713 (2009).

17. Kreneisz, O., Chen, X., Fridell, Y. W. \& Mulkey, D. K. Glucose increases activity and $\mathrm{Ca} 2+$ in insulin-producing cells of adult Drosophila. Neuroreport 21, 1116-1120, doi:10.1097/ WNR.0b013e3283409200 (2010).

18. Nassel, D. R., Kubrak, O. I., Liu, Y., Luo, J. \& Lushchak, O. V. Factors that regulate insulin producing cells and their output in Drosophila. Front Physiol. 4, 252, doi:10.3389/ fphys.2013.00252 (2013).

19. The FlyBase database of the Drosophila genome projects and community literature. Nucleic Acids Res. 31, 172-175 (2003).

20. Colombani, J. et al. A nutrient sensor mechanism controls Drosophila growth. Cell 114, 739-749 (2003).

21. Kwak, S. J. et al. Drosophila adiponectin receptor in insulin producing cells regulates glucose and lipid metabolism by controlling insulin secretion. PLoS One 8, e68641, doi:10.1371/ journal.pone.0068641 (2013).

22. Pool, A. H. et al. Four GABAergic interneurons impose feeding restraint in Drosophila. Neuron 83, 164-177, doi:10.1016/j. neuron.2014.05.006 (2014).

23. Okamoto, H. \& Nishimura, E. K. Signaling from Glia and Cholinergic Neurons Controls Nutrient-Dependent Production of an Insulin-like Peptide for Drosophila Body Growth. Dev. Cell 35, 295-310 (2015).

24. Rulifson, E. J., Kim, S. K.\& Nusse, R.Ablation of insulin-producing neurons in flies: growth and diabetic phenotypes. Science 296, 1118-1120, doi:10.1126/science.1070058 (2002).

25. R, N. D. \& J, V. B. Insulin/IGF signaling in Drosophila and other insects: factors that regulate production, release and postrelease action of the insulin-like peptides. Cell. Mol. Life Sci., doi:10.1007/s00018-015-2063-3 (2015).

26. Palu, R. A. S. \& Thummel, C. S. Linking Nutrients to Growth through a Positive Feedback Loop. Dev. Cell 35, 265-266, doi:http://dx.doi.org/10.1016/j.devcel.2015.10.026 (2015).

27. Brogiolo, W. et al. An evolutionarily conserved function of the Drosophila insulin receptor and insulin-like peptides in growth control. Curr. Biol. 11, 213-221 (2001).

28. Broughton, S. J. et al. Longer lifespan, altered metabolism, and stress resistance in Drosophila from ablation of cells making insulin-like ligands. Proceedings of the National Academy of Sciences of the United States of America 102, 3105-3110, doi:10.1073/pnas.0405775102 (2005).

29. Alic, N., Hoddinott, M. P., Vinti, G. \& Partridge, L. Lifespan extension by increased expression of the Drosophila homologue of the IGFBP7 tumour suppressor. Aging Cell 10, 137-147, doi:10.1111/j.1474-9726.2010.00653.x (2011).

30. Arquier, N. et al. Drosophila ALS regulates growth and metabolism through functional interaction with insulin-like peptides. Cell Metab. 7, 333-338, doi:10.1016/j.cmet.2008.02.003 (2008).

31. Okamoto, N. et al. A secreted decoy of InR antagonizes insulin/ IGF signaling to restrict body growth in Drosophila. Genes Dev. 27, 87-97, doi:10.1101/gad.204479.112 (2013).

32. Lee, K. S. et al. Drosophila short neuropeptide F signalling regulates growth by ERK-mediated insulin signalling. Nat. Cell Biol. 10, 468-475, doi:10.1038/ncb1710 (2008).

33. Kapan, N., Lushchak, O. V., Luo, J. \& Nassel, D. R. Identified peptidergic neurons in the Drosophila brain regulate insulin-producing cells, stress responses and metabolism by coexpressed short neuropeptide F and corazonin. Cell Mol. Life Sci. 69, 4051-4066, doi:10.1007/s00018-012-1097-z (2012). 
34. Kaplan, D. D., Zimmermann, G., Suyama, K., Meyer, T. \& Scott, M.P.Anucleostemin family GTPase, NS3, acts in serotonergic neurons to regulate insulin signaling and control body size. Genes Dev. 22, 1877-1893, doi:10.1101/gad.1670508 (2008).

35. Luo, J., Becnel, J., Nichols, C. D. \& Nassel, D. R. Insulin-producing cells in the brain of adult Drosophila are regulated by the serotonin 5-HT1A receptor. Cell Mol. Life Sci. 69, 471-484, doi:10.1007/s00018-011-0789-0 (2012).

36. Birse, R. T., Soderberg, J. A., Luo, J., Winther, A. M. \& Nassel, D. R. Regulation of insulin-producing cells in the adult Drosophila brain via the tachykinin peptide receptor DTKR. The Journal of experimental biology 214,4201-4208, doi:10.1242/jeb.062091 (2011).

37. Miyamoto, T., Wright, G. \& Amrein, H. Nutrient sensors. Curr. Biol. 23, R369-373, doi:10.1016/j.cub.2013.04.002 (2013).

38. Miyamoto, T. \& Amrein, H. Diverse roles for the Drosophila fructose sensor Gr43a. Fly (Austin) 8, 19-25, doi:10.4161/ fly.27241 (2014).

39. Nassel, D. R. \& Broeck, J. V. Insulin/IGF signaling in Drosophila and other insects: factors that regulate production, release and post-release action of the insulin-like peptides. Cell Mol. Life Sci., doi:10.1007/s00018-015-2063-3 (2015).

40. Lushchak, O. V., Carlsson, M. A. \& Nassel, D. R. Food odors trigger an endocrine response that affects food ingestion and metabolism. Cell Mol. Life Sci. 72, 3143-3155, doi:10.1007/ s00018-015-1884-4 (2015).

41. Fernández, R., Tabarini, D.,Azpiazu, N., Frasch, M.\& Schlessinger, J. The Drosophila insulin receptor homolog: a gene essential for embryonic development encodes two receptor isoforms with different signaling potential. Embo. J. 14, 3373-3384 (1995).

42. Bohni, R. et al. Autonomous control of cell and organ size by CHICO, a Drosophila homolog of vertebrate IRS1-4. Cell 97, 865-875 (1999).

43. Slack, C. et al. Regulation of lifespan, metabolism, and stress responses by the Drosophila SH2B protein, Lnk. PLoS Genet. 6, e1000881, doi:10.1371/journal.pgen.1000881 (2010).

44. Werz, C., Kohler, K., Hafen, E. \& Stocker, H. The Drosophila SH2B family adaptor Lnk acts in parallel to chico in the insulin signaling pathway. PLoS Genet. 5, e1000596, doi:10.1371/ journal.pgen.1000596 (2009).

45. Almudi, I., Poernbacher, I., Hafen, E. \& Stocker, H. The Lnk/ $\mathrm{SH} 2 \mathrm{~B}$ adaptor provides a fail-safe mechanism to establish the Insulin receptor-Chico interaction. Cell Commun. Signal 11, 26, doi:10.1186/1478-811X-11-26 (2013).

46. Leevers, S. J., Weinkove, D., MacDougall, L. K., Hafen, E. \& Waterfield, M. D. The Drosophila phosphoinositide 3-kinase Dp110 promotes cell growth. Embo. J. 15, 6584-6594 (1996).

47. Alessi, D. R. et al. 3-Phosphoinositide-dependent protein kinase-1 (PDK1): structural and functional homology with the Drosophila DSTPK61 kinase. Curr. Biol. 7, 776-789 (1997).

48. Verdu, J., Buratovich, M.A., Wilder, E. L. \& Birnbaum, M. J. Cellautonomous regulation of cell and organ growth in Drosophila by Akt/PKB. Nat. Cell Biol. 1, 500-506, doi:10.1038/70293 (1999).

49. Huang, H. et al. PTEN affects cell size, cell proliferation and apoptosis during Drosophila eye development. Development 126, 5365-5372 (1999).

50. Papadopoulou, D., Bianchi, M. W. \& Bourouis, M. Functional studies of shaggy/glycogen synthase kinase 3 phosphorylation sites in Drosophila melanogaster melanogaster. Mol. Cell Biol. 24,4909-4919, doi:10.1128/MCB.24.11.4909-4919.2004 (2004).

51. Junger, M. A. et al. The Drosophila forkhead transcription factor FOXO mediates the reduction in cell number associated with reduced insulin signaling. $J$ Biol 2, 20, doi:10.1186/14754924-2-20 (2003).

52. Kramer, J. M., Slade, J. D. \& Staveley, B. E. foxo is required for resistance to amino acid starvation in Drosophila. Genome 51, 668-672, doi:10.1139/G08-047 (2008).

53. Kramer, J. M., Davidge, J. T., Lockyer, J. M. \& Staveley, B. E. Expression of Drosophila FOXO regulates growth and can phenocopy starvation. BMCDev. Biol. 3, 5, doi:10.1186/1471213X-3-5 (2003).

54. Potter, C. J., Huang, H. \& Xu, T. Drosophila Tsc1 functions with Tsc2 to antagonize insulin signaling in regulating cell growth, cell proliferation, and organ size. Cell 105, 357-368 (2001).

55. Tapon, N., Ito, N., Dickson, B. J., Treisman, J. E. \& Hariharan, I. K. The Drosophila tuberous sclerosis complex gene homologs restrict cell growth and cell proliferation. Cell 105, 345-355 (2001).

56. Ito, N. \& Rubin, G. M. gigas, a Drosophila homolog of tuberous sclerosis gene product-2, regulates the cell cycle. Cell 96, 529-539 (1999).

57. Zhang, Y. et al. Rheb is a direct target of the tuberous sclerosis tumour suppressor proteins. Nat. Cell Biol. 5, 578-581, doi:10.1038/ncb999 (2003)

58. Saucedo, L. J. et al. Rheb promotes cell growth as a component of the insulin/TOR signalling network. Nat. Cell Biol. 5, 566571, doi:10.1038/ncb996 (2003).

59. Potter, C. J., Pedraza, L. G. \& Xu, T. Akt regulates growth by directly phosphorylating Tsc2. Nat. Cell Biol. 4, 658-665, doi:10.1038/ncb840 (2002).

60. Wang, B. et al. A hormone-dependent module regulating energy balance. Cell 145, 596-606, doi:10.1016/j.cell.2011.04.013 (2011).

61. Oldham, S. \& Hafen, E. Insulin/IGF and target of rapamycin signaling: a TOR de force in growth control. Trends Cell Biol. 13, 79-85 (2003).

62. Seto, B. Rapamycin and mTOR: a serendipitous discovery and implications for breast cancer. Clin. Transl. Med. 1, 29, doi:10.1186/2001-1326-1-29 (2012).

63. Kim, E., Goraksha-Hicks, P., Li, L., Neufeld, T. P. \& Guan, K. L. Regulation of TORC1 by Rag GTPases in nutrient response. Nat. Cell Biol. 10, 935-945, doi:10.1038/ncb1753 (2008).

64. Chantranupong, L., Wolfson, R. L. \& Sabatini, D. M. Nutrientsensing mechanisms across evolution. Cell 161, 67-83, doi:10.1016/j.cell.2015.02.041 (2015).

65. Li, L. et al. Regulation of mTORC1 by the Rab and ArfGTPases. $J$. Biol. Chem. 285, 19705-19709, doi:10.1074/jbc.C110.102483 (2010).

66. Miron, M., Lasko, P. \& Sonenberg, N. Signaling from Akt to FRAP/ TOR targets both 4E-BP and S6K in Drosophila melanogaster. Mol. Cell Biol. 23, 9117-9126 (2003).

67. Stewart, M. J., Berry, C. O., Zilberman, F., Thomas, G. \& Kozma, S. C. The Drosophila p70s6k homolog exhibits conserved regulatory elements and rapamycin sensitivity. Proceedings of the National Academy of Sciences of the United States of America 93, 10791-10796 (1996).

68. Montagne, J. et al. Drosophila S6 kinase: a regulator of cell size. 
Science 285, 2126-2129 (1999).

69. Hernández, G. \& Sierra, J. M. Translation initiation factor eIF-4E from Drosophila: cDNA sequence and expression of the gene. Biochimica et biophysica acta 1261, 427-431 (1995).

70. Hardie, D. G. \& Pan, D. A. Regulation of fatty acid synthesis and oxidation by the AMP-activated protein kinase. Biochem. Soc. Trans. 30, 1064-1070, doi:10.1042/ (2002).

71. Pan, D. A. \& Hardie, D. G. A homologue of AMP-activated protein kinase in Drosophila melanogaster is sensitive to AMP and is activated by ATP depletion. Biochem. J. 367, 179-186, doi:10.1042/BJ20020703 (2002).

72. Haselton, A. T. \& Fridell, Y. W. Adult Drosophila melanogaster as a model for the study of glucose homeostasis. Aging (Albany NY) 2, 523-526 (2010).

73. Baker, K. D. \& Thummel, C. S. Diabetic larvae and obese fliesemerging studies of metabolism in Drosophila. Cell Metab. 6, 257-266, doi:10.1016/j.cmet.2007.09.002 (2007).

74. Murillo-Maldonado, J. M., Sánchez-Chávez, G., Salgado, L. M., Salceda, R. \& Riesgo-Escovar, J. R. Drosophila insulin pathway mutants affect visual physiology and brain function besides growth, lipid, and carbohydrate metabolism. Diabetes 60, 1632-1636, doi:10.2337/db10-1288 (2011).

75. Murillo-Maldonado, J. M.,Zeineddine, F. B., Stock, R., Thackeray, J. \& Riesgo-Escovar, J. R. Insulin receptor-mediated signaling via phospholipase C-gamma regulates growth and differentiation in Drosophila. PLoS One 6, e28067, doi:10.1371/journal. pone.0028067 (2011).

76. Haselton, A. et al. Partial ablation of adult Drosophila insulinproducing neurons modulates glucose homeostasis and extends life span without insulin resistance. Cell Cycle 9, 3063-3071, doi:10.4161/cc.9.15.12458 (2010).

77. Casanueva, E., Kaufer-Horwitz, M., Pérez-Lizaur,A. B. \& Arroyo, P. Nutriología Médica. (Editorial Médica Panamericana, 2008).

Se pueden consultar artículos de reciente aparición de los autores de este manuscrito en el siguiente link http://132.248.142.23/web_site/ home_pages $/ 88$ 